\title{
iPlanetário - Da Terra ao Universo
}

\author{
Bernardo Pereira Nunes ${ }^{1,3}$, Igor de O. Martins ${ }^{1}$, Gilda Helena B. de Campos ${ }^{1,2}$, \\ Bruna Heinsfeld ${ }^{2}$, Alexandre Cherman ${ }^{4}$, Luís Guilherme Haun ${ }^{4}$ \\ ${ }^{1}$ Coordenação Central de Educação a Distância - PUC-Rio \\ ${ }^{2}$ Departamento de Educação - PUC-Rio \\ ${ }^{3}$ Departamento de Informática - PUC-Rio \\ ${ }^{4}$ Fundação Planetário da Cidade do Rio de Janeiro
}

\{bernardo,igor,gilda\}@ccead.puc-rio.br, brunadamiana@gmail.com, \{alexandre.cherman, luis.haun\}@rio.rj.gov.br

Resumo. Neste trabalho apresentamos o iPlanetário, uma plataforma interativa dispondo de 44 recursos midiáticos formativos e informativos sobre fenômenos científicos na área de Astronomia. O iPlanetário tem como seus principais objetivos: (i) levar os conhecimentos básicos e necessários para a compreensão da Astronomia aos professores e alunos da rede de ensino (pública e privada), seguindo os Parâmetros Curriculares Nacionais e as orientações da Base Nacional Curricular Comum; (ii) preencher uma lacuna que existe na formação dos professores dos ensinos fundamental e médio; (iii) motivar jovens para que no futuro escolham uma carreira científica; e (iv) atuar na divulgação científica da Astronomia. O iPlanetário está disponível em duas versões: Web e App garantindo e possibilitando o acesso on-line e off-line para um amplo público interessado na aprendizagem de Astronomia.

\section{Cenário de Uso}

O projeto do software educacional iPlanetário consiste em uma plataforma interativa e recursos midiáticos formativos e informativos sobre os fenômenos científicos que servem como guia ou itinerários para professores e alunos dos diversos segmentos escolares. Desenvolvido em parceria com astrônomos da Fundação Planetário da Cidade do Rio de Janeiro, o projeto emerge da necessidade de preenchimento da lacuna existente na oferta de conteúdos e atividades relacionados à Astronomia para crianças e jovens dos Ensinos Fundamental e Médio brasileiros, não se restringindo, contudo, a esse público-alvo.

De acordo com os Parâmetros Curriculares Nacionais (PCN), a Astronomia deve fazer parte do currículo escolar, sendo incluída no eixo das Ciências Naturais desde o primeiro ciclo do Ensino Fundamental (BRASIL, 1998a). Para os ciclos finais, os PCN apresentam a unidade temática Terra e Universo como unidade obrigatória, contemplando questões relacionadas à Astronomia e a suas possíveis interdisciplinaridades (BRASIL, 1998b). Em complementariedade, a atual Base Nacional Curricular Comum (BNCC) detalha para o mesmo segmento os conteúdos sobre a unidade Terra e Universo, na qual é explorada a temática da Astronomia, em especial a compreensão das características da Terra, do Sol e da Lua, em relação com o Universo e com a posição do ser humano nesse contexto (BRASIL, 2017).

No entanto, embora haja a obrigatoriedade legal desse letramento científico, é sabido que há, ainda hoje, um déficit na oferta de docentes qualificados para a atuação 
VI Congresso Brasileiro de Informática na Educação (CBIE 2017)

Anais dos Workshops do VI Congresso Brasileiro de Informática na Educação (WCBIE 2017)

com tais temáticas em sala de aula. Uma das possíveis explicações para esse déficit está na inexistência em território nacional do curso de licenciatura específica em Astronomia, sendo os professores licenciados em Física responsáveis pelo trabalho com esses conteúdos. Ademais, entendemos que a questão da infraestrutura nas escolas públicas também se apresenta como um elemento inviabilizador do processo, considerando as restrições físicas e econômicas ou mesmo os graus de periculosidade para a simulação e/ou reprodução de determinados experimentos no ambiente escolar, impossibilitando que os alunos tenham uma experiência plena com os conteúdos relacionados à área.

Dado esse cenário, o software educacional iPlanetário busca oferecer um aporte didático e sistematizado do conhecimento escolar sobre a Astronomia, proporcionando suporte tanto para alunos quanto para professores na compreensão dos temas escolhidos. Além da tentativa de suprir as lacunas encontradas, busca-se envolver os alunos, atuando no letramento científico a partir da consolidação do conhecimento da Astronomia e áreas correlatas da ciência-tecnologia como uma forma de cultura, nos utilizando, para tanto, dos museus, planetários e centros de ciências como ponto de partida.

Em consonância com a proposta de letramento científico, Gee (2010) pontua que uma das ocupações dos multiletramentos está na forma como os sujeitos (res)significam as mídias e recebem significados a partir delas, buscando entender como esse processo de significação pode ser mais crítico e reflexivo. Nesse sentido, os processos de novos letramentos englobam tanto ler quanto significar, ressignificar e recriar o mundo a volta, a partir das interações com as mídias e tecnologias do cotidiano (WILSON, 2013). Lemke (2010), por sua vez, afirma o que os núcleos educacionais na sociedade moderna devem, antes de tudo, perceber que os multiletramentos, aliados a diversas tradições culturais, são combinados e recombinados para extrapolar seus próprios significados e construir novos. É relevante realçar, seguindo a perspectiva da ciência como um projeto humano histórico, social e culturalmente construído, a intencionalidade da abordagem inter, multi e transdisciplinar dos conteúdos de Astronomia, como uma forma de criar situações que levem ao letramento científico (SHAMOS, 1995 apud SANTOS, 2007).

Ao falarmos da relação dos espaços museais com nossa sociedade, em especial dos museus de ciência, faz-se necessário levar em consideração as profundas e marcantes mudanças pelas quais vêm passando: se anteriormente eram vistos como armazéns de objetos antigos, hoje são considerados espaços que propiciam a aprendizagem ativa (VALENTE, CAZELLI e ALVES, 2005). Seguindo a tendência da "Museologia da Ideia” (MONTEPETIT, 1998 apud VALENTE, CAZELLI e ALVES, 2005), que recorre a um conjunto de técnicas de comunicação digital para tornar as práticas sociais mais atrativas, transmitindo informações aos visitantes e motivando-os, buscamos o desenvolvimento de recursos midiáticos cuja adoção amplia e apoia o processo ensino-aprendizagem nas escolas. Partindo dessa perspectiva, concordamos que a função primária de um museu de ciência é o diálogo entre a comunicação e o saber, sendo a interatividade uma poderosa ferramenta, capaz de, usando a ludicidade, entreter, informar e desafiar oferecendo ao público uma pedagogia não consciente e não diretiva.

Inicialmente destinado para planetários, museus e centros de ciência, o software educacional desenvolvido sob o formato m-learning pode ter seu uso ampliado para as 
salas de aula físicas ou virtuais, como material complementar ou de apoio sobre Astronomia. Contendo cinco grandes áreas temáticas - Terra; Terra-Lua; Sistema Solar; Via Láctea e Universo - a plataforma traça um panorama desde o planeta Terra em que vivemos e conhecemos, até o vasto Universo e aquilo que se desconhece. A abordagem dos temas ligados à Astronomia em campos temáticos com níveis de percepção cada vez mais amplos tem o objetivo de partir do primeiro obstáculo epistemológico: a experiência primeira, ou seja, a percepção comum que temos do mundo filtrada pelos olhos e cultura (BACHELARD, 1996). Essa escolha é um convite às concepções prévias dos estudantes para participar do processo de tomada de consciência e explicitação, de tal forma que, a partir desse contato, se produzam reflexões cientificamente mais coerentes com a existência do mundo que nos cerca.

\section{Desenvolvimento}

Hoje, os conhecimentos e as habilidades cuja aprendizagem se fazem necessários não são os mesmos daqueles que virão a ser necessários nos próximos cinco anos, de forma que a definição e o planejamento desses itens se mostram uma árdua tarefa no campo educacional. Nesse sentido, autores como Gabriel (2013), Lemke (2010), Lévy (2014) e Pretto; Pinto (2006) problematizam em que contexto social nos encontramos e quais seriam as habilidades essenciais para a atuação cidadã no futuro, tendo como base a reflexão sobre quais seriam as competências estratégicas para essa nova era. Parece haver consenso entre os especialistas no que diz respeito à tônica dessas habilidades, que gira em torno do desenvolvimento do pensamento crítico, da habilidade de solução de problemas, do entendimento e da apropriação do funcionamento das redes colaborativas, em especial das possibilidades da inteligência coletiva, da adaptabilidade e da resiliência, da criatividade, da curiosidade, da iniciativa e do empreendedorismo, e, não menos importante, das faculdades de pesquisa, acesso, análise e avaliação das informações disponíveis. No desenvolvimento do projeto, levou-se em consideração não só o papel central dos meios digitais no cotidiano social, mas, ainda, tais habilidades consideradas essenciais para a formação no século XXI. Dentre elas, ressaltamos o pensamento crítico e a solução de problemas, a iniciativa, a análise crítica de informações, a criatividade e o protagonismo, viabilizados através das atividades propostas no iPlanetário.

Pensando no impacto do uso das tecnologias digitais na educação, nos apropriamos das potencialidades emergentes da mobilidade e da ubiquidade, tendo escolhido o m-learning como plataforma de aprendizagem, sendo o iPlanetário inicialmente disponibilizado para dispositivos móveis localizados em totens interativos nos planetários e museus. Buscando fundamentar nossas opções didáticas, recorremos aos estudos sobre a produção de materiais didáticos e objetos de aprendizagem, que pautaram o desenvolvimento dos recursos disponibilizados na plataforma. De acordo com Moran (2013), há componentes fundamentais para o sucesso do ensinoaprendizagem, entre eles o desenvolvimento de desafios, atividades e jogos incorporados às atividades didáticas. Para tanto, as estratégias pedagógicas devem trazer à tona as competências necessárias, estimulando a motivação. Nesse cenário, o design didático - descrito aqui brevemente como a concepção e o desenvolvimento de situações didáticas específicas, visando a otimização da aprendizagem (CAMPOS, ROQUE e AMARAL, 2007) -, tem sido apontado por estudiosos da área como um dos elementos principais não só no macroplanejamento de cursos, como no 
desenvolvimento de objetos de aprendizagem e de atividades didáticas. Para que o resultado final seja eficiente, o processo do design didático deve incluir desde a concepção ampla do material, transitando pela filosofia educacional e pelas teorias de aprendizagem, até o nível mais específico, concreto, como o refinamento das unidades de estudo, o texto didático do material e a elaboração de atividades (BARRETO, 2007; CAMPOS, ROQUE e AMARAL, 2007; FILATRO, 2009, 2010; FILATRO e CAIRO, 2015). Além disso, considera-se que, para que as tecnologias digitais possam ser incorporadas e potencializar o processo ensino-aprendizagem, é preciso considerar suas especificidades (GUTIERREZ e PRIETO, 1994; KENSKI, 2007).

Em diálogo com essas premissas, após a análise dos conteúdos, definiu-se o formato de apresentação mais adequado para o recurso midiático, resultando na organização temática já citada, além das estratégias de entrada (motivadora), de desenvolvimento (apresentação de conceitos, experiências) e de encerramento (síntese e/ou propostas), contempladas pelo material disponibilizado no iPlanetário através das atividades propostas em formato de jogos, quizzes, vídeos, simulações e desafios, além de textos explicativos, animações e sons organizados hipertextualmente, trabalhando com a convergência das mídias. Assim, é possível representar/simular virtualmente processos e fenômenos usando linguagem metafórica, representações conhecidas para os estudantes ou aproximações fiéis do que acontece em dimensões de realidade de difícil observação. Os formatos contidos no software educacional procuram estimular a imaginação, a formulação de hipóteses, o controle de variáveis e de etapas de uma observação ou experimento, assim como a tomada de decisão e a verificação de resultados pelos alunos. Deste modo, contribuem para uma aprendizagem intuitiva, para a ressignificação de conteúdos e para um processo ensino-aprendizagem lúdico, aguçando a curiosidade pelos temas. Além disso, considerando o protagonismo e a iniciativa dos jovens, parte dos objetos desenvolvidos foram sugeridos a partir da campanha "Você no Planetário" com o objetivo de reunir as curiosidades e dúvidas comuns ao público-alvo e a comunidade a ser atendida. Dessa forma, foi garantida a participação ativa dos alunos no processo, procurando trabalhar, dentro das temáticas obrigatórias, as questões de maior interesse do público-alvo.

Do ponto de vista técnico, o App do iPlanetário foi projeto sob preceitos básicos de usabilidade, interatividade e navegabilidade permitindo uma fácil navegação bem como aprendizagem e acesso rápido e estruturada aos objetos por seus usuários. O App está licenciado segundo os termos da Creative Commons 4.0 de atribuição, nãocomercial e compartilhamento, permitindo assim o seu reuso, adaptação e reprodução de forma não-comercial.

Considera-se o App iPlanetário uma plataforma MultiApp, i.e., um App capaz de abrigar, encapsular e reproduzir Apps independentes de forma estruturada e predefinida (ver Figura 1). O MultiApp foi desenvolvido utilizando a linguagem Swift 2.0, o que permite sua execução em dispositivos móveis com sistema operacional iOS. Já os demais objetos foram desenvolvidos utilizando tecnologias Web (HTML5, CSS, Javascript) encapsuladas como Apps, sendo assim possível a sua execução através do MultiApp e, também, via Web. Uma versão dos aplicativos Web pode ser acessada através do link: https://goo.gl/AkrMDY enquanto que um vídeo-teaser da plataforma e seus objetos encontra-se no link: https://goo.gl/1uarSb. Ao todo a plataforma possui 44 objetos de aprendizagem entre jogos, animações, minicursos, entrevistas. 


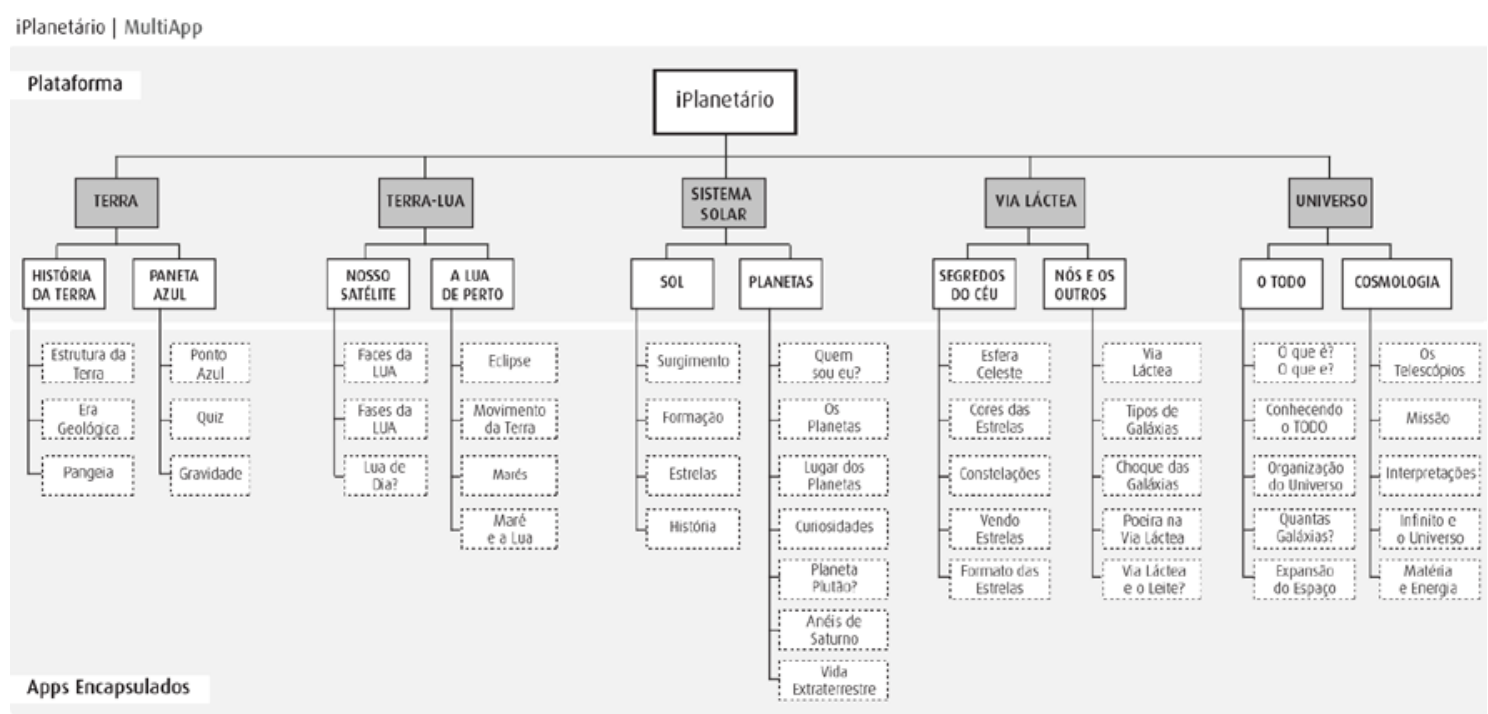

Figura 1. Estrutura da Plataforma e Objetos que compõem o iPlanetário.

Ainda, é contemplado na plataforma o uso de logs das interações, visando o auxílio no desenvolvimento futuro e incorporação na plataforma iPlanetário objetos de aprendizagem mais alinhados ao público-alvo e às suas necessidades e interesses.

\section{Apresentação do Software}

A plataforma MultiApp pode ser vista na Figura 2a, onde o usuário pode optar por conhecer os tópicos Terra, Terra-Lua, Sistema Solar, Via-Láctea, Universo. Ao escolher um dos tópicos o usuário poderá navegar pelos subtemas (na versão para dispositivos móveis) ou navegar pelos objetos de aprendizagem diretamente (apenas na versão Web). Abaixo disponibilizamos alguns exemplos de objetos encontrados no iPlanetário (ver Figura 2b-f), comentando brevemente sobre o funcionamento e as vantagens de cada formato.

Na Figura 2b ilustramos um objeto de aprendizagem no formato de Quiz, onde uma dica é apresentada e o usuário deve escolher uma entre as opções disponíveis para solucionar a charada. A cada rodada, aparece uma nova dica e três opções para que o aluno escolha. O formato é dinâmico, com feedback imediato, estimulando a conexão com os conhecimentos construídos em sua visita ao planetário, a partir do trabalho com a identificação e revisão dos conceitos. Na Figura 2c temos um exemplo de tela expositiva, em que um conteúdo é apresentado ao aluno de maneira interativa, orientando sua aprendizagem a partir de representações imagéticas combinadas ao texto, resumindo de forma didática as eras geológicas.

A Figura 2d ilustra um exemplo de jogo drag n'drop para organização dos planetas no sistema solar. De fácil mecânica, o jogo busca aumentar a retenção dos conteúdos e facilitar a construção do conhecimento pelo aluno, oferecendo uma nova forma de praticar o conhecimento construído ao longo da visita ao planetário, promovendo o engajamento a partir do desafio. Já a Figura 2e ilustra um novo jogo, no qual o aluno tem a possibilidade de ampliar seus conhecimentos relacionado aos cientistas que estudaram o universo. A missão é conduzir a nave de forma segura por uma chuva de meteoros, sem que seja atingida. Ao final de cada onda de meteoros, caso seja bem-sucedido em sua missão, o aluno recebe como prêmio uma carta diferente com informações sobre um cientista. Ao fornecer uma carta com novos conteúdos como 
VI Congresso Brasileiro de Informática na Educação (CBIE 2017)

Anais dos Workshops do VI Congresso Brasileiro de Informática na Educação (WCBIE 2017)

prêmio pela vitória, reforça-se, ainda, o saber como bem valioso. A Figura 2f, por sua vez, mostra um dos vídeos da série de perguntas e respostas "Você no planetário", respondidas pelo astrônomo do Planetário do Rio. As perguntas foram enviadas por alunos e pela comunidade sobre o tema, a partir das quais também se desenvolveram os objetos de aprendizagem. Como mencionado anteriormente, a partir dessa estratégia, foi possível engajar o público no desenvolvimento do projeto, atuando sobre as temáticas que mais despertavam a curiosidade, além daquelas já dispostas nas normas curriculares.

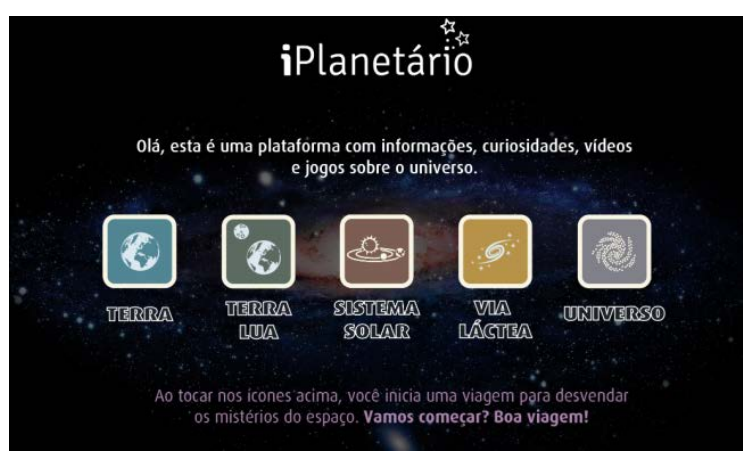

2a) Tela Inicial do iPlanetário (versão App)

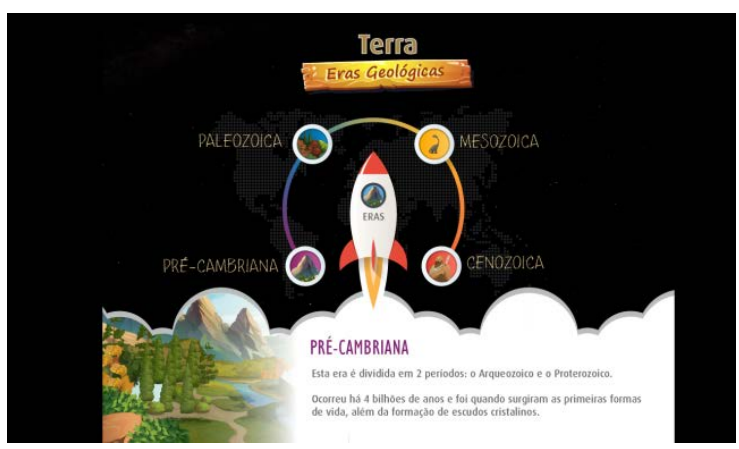

2c) Exemplo de recurso sobre as Eras Geológicas

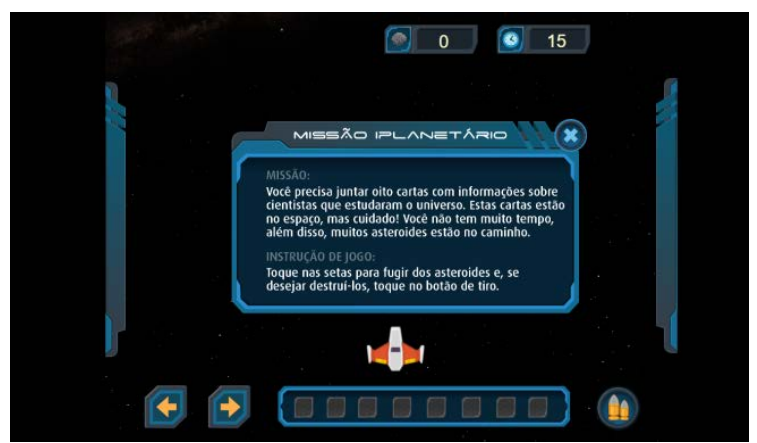

2e) Exemplo de Jogo para conhecer mais sobre os cientistas que estudaram o universo

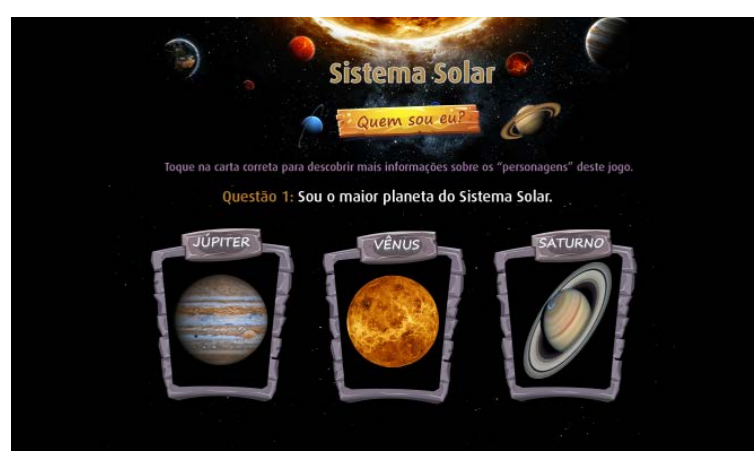

2b) Exemplo de Quiz sobre o Sistema Solar

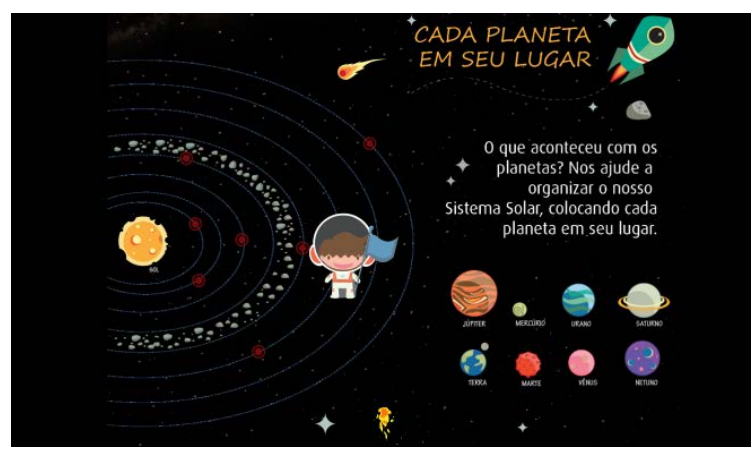

2d) Exemplo de Jogo Drag n’ Drop para

Organização dos Planetas no Sistema Solar

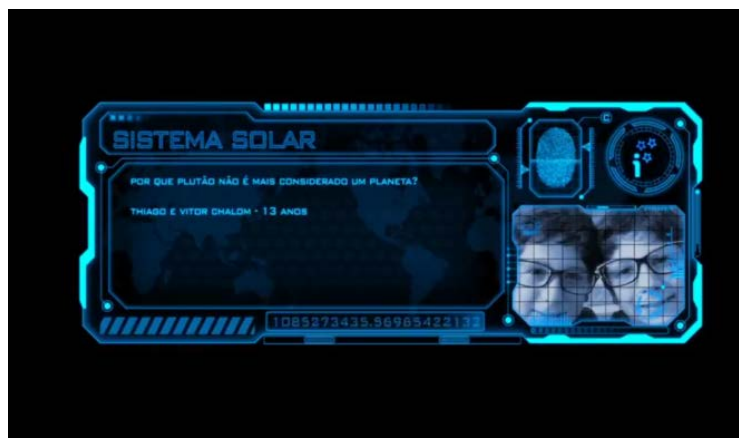

2f) Exemplo de Vídeo com Respostas para as Perguntas do Você no Planetário 
VI Congresso Brasileiro de Informática na Educação (CBIE 2017)

Anais dos Workshops do VI Congresso Brasileiro de Informática na Educação (WCBIE 2017)

\section{Considerações Finais}

Neste trabalho apresentamos o MultiApp iPlanetário, uma plataforma interativa com recursos midiáticos formativos e informativos sobre fenômenos científicos na área de Astronomia. O iPlanetário teve como objetivos: (1) levar os conhecimentos básicos e necessários para a compreensão da Astronomia aos professores e alunos da rede de ensino (pública e privada), seguindo os Parâmetros Curriculares Nacionais e as orientações da Base Nacional Curricular Comum; (2) preencher uma lacuna que existe na formação dos professores dos ensinos fundamental e médio; (3) motivar jovens para que no futuro escolham uma carreira científica; e (4) atuar na divulgação científica da Astronomia.

Através de uma licença Creative Commons 4.0 o iPlanetário está disponível de forma não-comercializável e pode ser acessada de forma irrestrita através da Web ou em Planetários através de totens instalados com dispositivos móveis. Desta forma, o acesso on-line ou off-line é garantido abrangendo e possibilitando a aprendizagem de Astronomia, seja de forma complementar as atividades das instituições de ensino interessadas ou em museus, planetários e centros de ciências.

Como trabalhos futuros pretende-se analisar os registros das ações dos usuários e os acessos dos objetos de aprendizagem na Web para o desenvolvimento focado no interesse e necessidade dos usuários. Além disso, pretende-se desenvolver objetos de aprendizagem nas áreas de Física e Química reutilizando a plataforma MultiApp desenvolvida para o iPlanetário.

\section{Agradecimentos}

O desenvolvimento do iPlanetário foi financiado pela FAPERJ E-26/010.001952/2014.

\section{Referências}

BACHELARD, G. A formação do espírito científico: contribuição para uma psicanálise do conhecimento. Rio de Janeiro: Contraponto, 1996.

BARRETO, C. C. (org.). Planejamento e elaboração de material didático impresso para educação a distância. Rio de Janeiro: Fundação CECIERJ, 2007, 291p.

BECKER, W. R.; STRIEDER, D. M. O uso de simuladores no ensino de astronomia. Anais do II ENINED - Encontro Nacional de Informática e Educação. Disponível em: <http://www.inf.unioeste.br/enined/anais/artigos_enined/A43.pdf > . Acesso em: 18 de out 2013.

BRASIL. Secretaria de Educação Fundamental. Parâmetros curriculares nacionais: Ciências Naturais/Secretaria de Educação Fundamental I. Brasília: MEC/SEF, 1998a. Disponível em: < http://portal.mec.gov.br/seb/arquivos/pdf/livro04.pdf >. Acesso em: 21 jun. 2017.

BRASIL. Secretaria de Educação Fundamental. Parâmetros curriculares nacionais: Ciências Naturais/Secretaria de Educação Fundamental II. Brasília: MEC/SEF, 1998b. Disponível em: <http://portal.mec.gov.br/seb/arquivos/pdf/ciencias.pdf $>$. Acesso em: 21 jun. 2017.

BRASIL, Ministério da Educação (MEC/SEED). Base Nacional Comum Curricular. $3^{\text {a }}$ versão revista. Brasília, 2017. Disponível em < 
VI Congresso Brasileiro de Informática na Educação (CBIE 2017)

Anais dos Workshops do VI Congresso Brasileiro de Informática na Educação (WCBIE 2017)

http://basenacionalcomum.mec.gov.br/images/BNCC_publicacao.pdf>. Acesso em: 18 jun. 2017.

CAMPOS, G. H. B.; ROQUE, G. O.; AMARAL, S. B. Dialética da Educação a Distância. 1. ed. Rio de Janeiro: Editora PUC-Rio, 2007. v. 1. 95p.

FILATRO, A. Design instrucional na prática. São Paulo: Pearson Education do Brasil, 2009, 173p.

Design instrucional contextualizado: educação e tecnologia. São Paulo: Senac, 2010, 215p.

FILATRO, A.; CAIRO, S. Produção de conteúdos educacionais. São Paulo: Saraiva, 2015, 462p.

GABRIEL, M. Educ@r - A (r)evolução digital na educação. São Paulo: Saraiva, 2013. $241 \mathrm{p}$.

GEE, J. P. A situated sociocultural approach to literacy and technology. In: The New Literacies: Multiple perspectives on research and practice. Editado por Elizabeth E. Baker. Nova Iorque: The Guilford Press, 2010.

GUTIÉRREZ, F.; PRIETO, D. A Mediação Pedagógica: educação à distância alternativa. São Paulo: Cortez; Instituto Paulo Freire, 1994.

KENSKI, V. M.; Educação e Tecnologias: o novo ritmo da informação. Campinas, SP: Papirus, 2007.

LEMKE, J. L. Letramento metamidiático: transformando significados e mídias. Trab. Ling. Aplic., Campinas, v. 49, n. 2, p. 455-479, jul./dez. 2010.

LÉVY, P. Cibercultura. São Paulo: Editora 34, 2014. 272 p.

MORAN, J. Metodologias ativas para uma aprendizagem mais profunda. 2013. Disponível em <http://www2.eca.usp.br/moran/wpcontent/uploads/2013/12/metodologias_moran1.pdf>. Acesso: em: 22 jun. 2017.

PRETTO, N.; PINTO, C. da C. Tecnologias e novas educações. Revista Brasileira de Educação, Rio de Janeiro, v. 11, n. 31, jan./abr. 2006.

SANTOS, W. L. P. Educação científica na perspectiva de letramento como prática social: funções, princípios e desafios. Revista Brasileira de Educação v. 12 n. 36 set./dez. $2007 . \quad$ Disponível em: <http://www.scielo.br/pdf/rbedu/v12n36/a07v1236.pdf>. Acesso em: 18 de out 2013.

SCARINCI, A. L.; PACCA, J. L. de A. Um Curso de Astronomia e as Pré-Concepções dos Alunos. Revista Brasileira de Ensino de Física, São Paulo, v.28, n.1, 89-99, 2006.

VALENTE, M. E., CAZELLI, S.; ALVES, F. Museus, ciência e educação: novos desafios. História, Ciências, Saúde - Manguinhos, vol. 12 (suplemento), p. 183-203, 2005. Disponível em: <http://www.scielo.br/pdf/hcsm/v12s0/09>. Acesso em: 18 out 2013.

WILSON, C. An introduction to media and information literacy. In: UNESCO. Media and information literacy for knowledge societies. Moscow: Interregional Library Cooperation Centre, 2013, p. 55-62. 